\author{
Adrian Augustin POP $P^{1,2,3}$ \\ Frédéric GILLON ${ }^{1,2}$ \\ Mircea M. RADULESCU $\boldsymbol{U}^{3}$ \\ ${ }^{1}$ Univ. Lille Nord de France, F-59000, Lille, France \\ ${ }^{2}$ EC-Lille, L2EP, F-59650, Villeneuve d'Ascq, France \\ ${ }^{3}$ Technical University of Cluj-Napoca, Special Electric \\ Machines and Light Electric Traction (SEMLET) \\ Research Laboratory, RO-400114, Cluj-Napoca, Romania
}

\title{
MODELLING AND DESIGN OPTIMIZATION OF A SMALL AXIAL- FLUX BRUSHLESS PERMANENT-MAGNET MOTOR FOR ELECTRIC TRACTION PURPOSES
}

\begin{abstract}
This paper presents the modelling and design optimization of an axial-flux brushless permanent-magnet motor with one rotor-two stators configuration. This particular axialflux machine is suitable to traction applications. The reason is that, firstly, fixing of the stators may be arranged reasonably easily; secondly, the topology with two stators is able to operate even if one of its stators is electrically disconnected; thirdly, the axial loading of bearings is small due to the symmetry of the motor structure. A prototype machine was designed and manufactured for verifying the design optimization results.
\end{abstract}

In modelling of axial-flux brushless permanent-magnet motors (AFBPMMs) the fastness and accuracy of the computations are very important aspects. Using finiteelement (FE) field analysis, it is possible to consider 3$\mathrm{D}$ structure of the machine, but performing the computations is often too time-consuming. In order to evaluate quickly the performance of the AFBPMM, the 2-D FE analysis, which is usually performed on the average radius of the machine, is a time-saving option, especially if the model will further be optimized. The main idea of the design method is to subdivide the AFBPMM into independent computation planes and to use the average radius of the machine as a design plane. This approach is sufficiently accurate to predict the motor performance, if the magnet width is constant with respect to the pole pitch, which is a function of the stator radius.

In axial-flux machines, the airgap flux density is an important design parameter, having notable effect on the machine characteristics. Therefore, in order to optimize the machine performance, the airgap flux density must be determined correctly [1].

The airgap flux-density modelling method is based on Fourier-series development. This technique enables to identify the cross-coupling between different spatial and temporal field components, and thus provides a very useful insight into the relationship between different design variables and machine performances. First analysis is carried out for a slotless machine. Therefore, the magnetic field produced by the magnets in the airgap is a sum of spatial components. For the second analysis, the effect of stator slots on the magnetic field is accounted for. The solution is made for distributed- winding AFBPMM.
The prototype machine is a three-phase AFBPMM with one-rotor-two-stators topology and 4 pole-pairs. The rated power of the machine is $0.3 \mathrm{~kW}$ and the nominal rotational speed is $1500 \mathrm{rpm}$.

The permanent magnets (PMs) are of high-energy $\mathrm{NdFeB}$ type, and are glued on the slots of the solidiron disk-rotor.

The material of the stator core is a fully-processed electrical steel sheet M600-50A. The stator winding is a conventional three-phase star-connected single-layer lap winding.

\section{2-D AND 3-D FE SIMULATION}

The basic idea of the design method is to subdivide the AFBPMM into independent computation planes, and to use as the design plane that one of the machine average radius. This approach is sufficiently accurate to predict the motor performance.

The method of transforming the 3-D geometry of an axial flux machine into a corresponding 2-D model via a linear transformation is illustrated in Fig. $1, b$ and $c$. The 2-D representative design plane is set on the average radius of the AFBPMM [2].

The 2-D FE modelling based on Fourier-series development is further utilized in the AFBPMM design optimization for traction applications. The optimized motor performances are verified by comparison with those of the built prototype AFBPMM.

\section{SLOTLESS MACHINE SIMULATION}

One of the most important features of the motor is the airgap flux density. Therefore, in order to optimize the machine performance, the airgap flux density must 


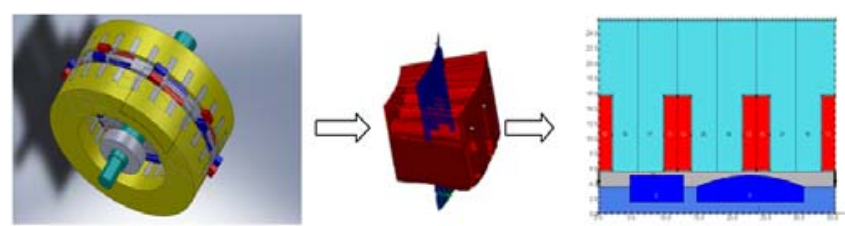

Fig.1 (a) Structure of the AFBPMM under study; (b) 3-D FEmodel for one magnetic pole; (c) 3-D model reduced to 2-D representative plane

be determined accurately.

Fig.2 displays the flux density distribution in the AFBPMM under study. The AFBPMM was simulated under no-load condition to monitor the airgap flux pattern. Fig. 4 shows the axial component of the no-load air-gap flux density due to rotor-PMs in the middle of the airgap plane.

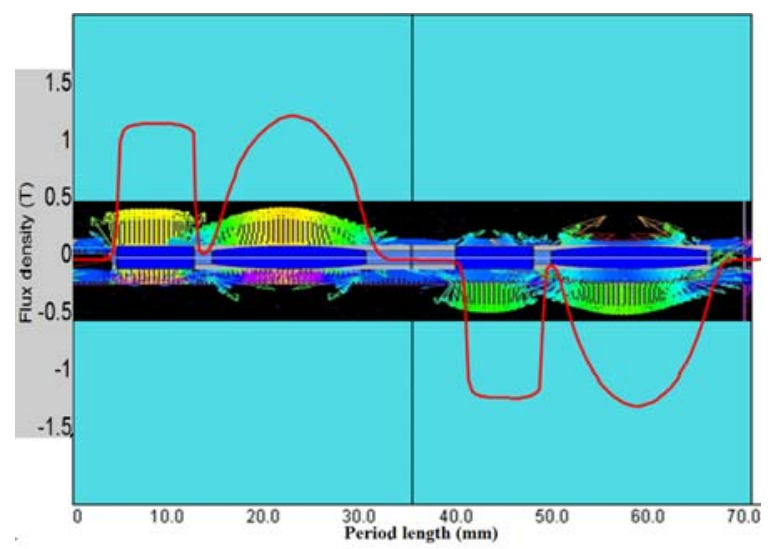

Fig.2 Flux-density distribution in the airgap of the AFBPMM under study.

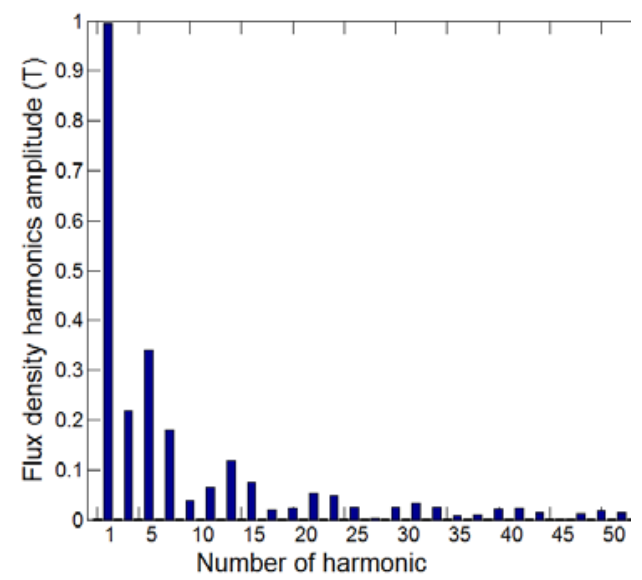

Fig.3 Frequency spectrum of the flux-density harmonics of the AFBPMM under study.

An extended modelling method is based on Fourier-series development. This technique considers the time-space distribution of electromagnetic variables so that it enables to identify the crosscoupling between different spatial and temporal field components. Therefore, it provides a very interesting insight into the correlation between different design variables and machine performances.

The shape of the spatial waveform is defined by solving in polar coordinates the magnetic potential equations in the air-gap. The frequency spectrum of flux density is presented in Fig.3. It shows that the main harmonic in the flux-density spectrum is the first-order harmonic and then the third harmonic. Fifth- and seventh-order airgap flux-density harmonics are also significant.

In axial-flux permanent magnet machines, there is an axial non-compensated force between rotor magnets and stator teeth. Fig. 4 depicts schematically this axial force, while Fig.5 stands out the rotor-PM distribution. There are two rotor-PMs for each magnetic pole, having different positions with respect to the stator teeth. The axial force fluctuations correspond to the angular recurrence of these relative pole-teeth positions.

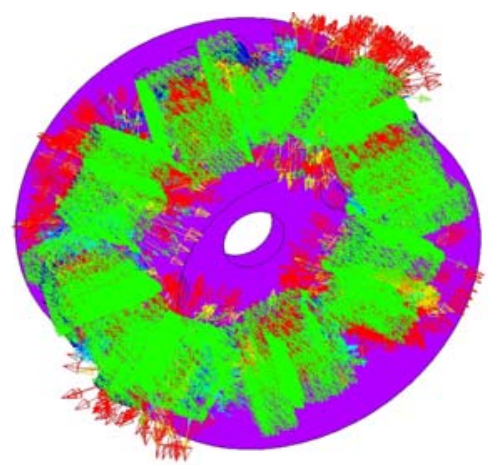

Fig.4 Schematic representation of axial forces in the AFBPMM under study.

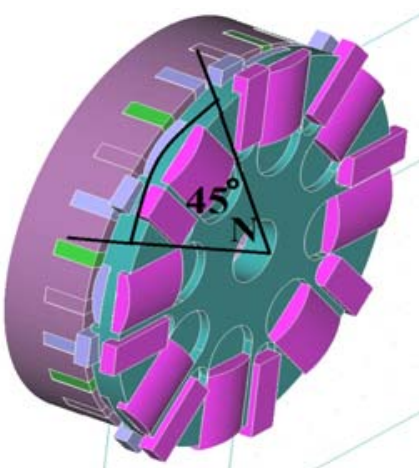

Fig.5 One of the two stators and the rotor with its PM arrangement.

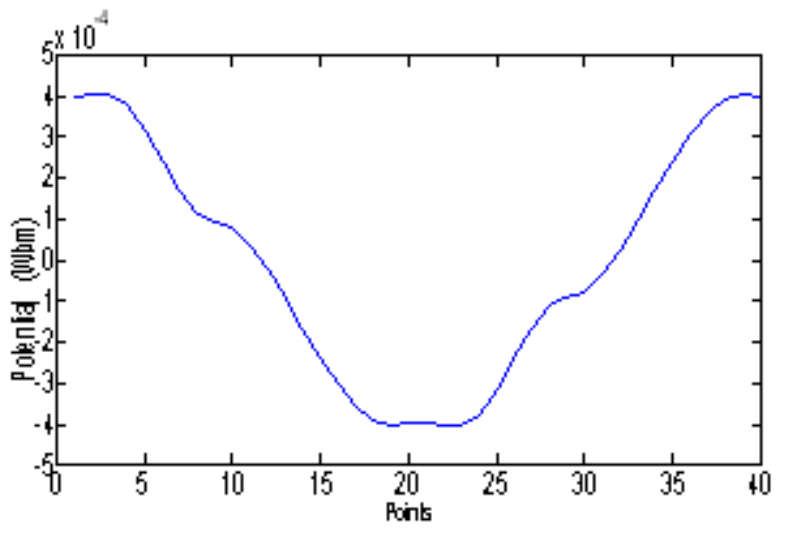

Fig.6 Magnetic potential distribution in the stator core. 


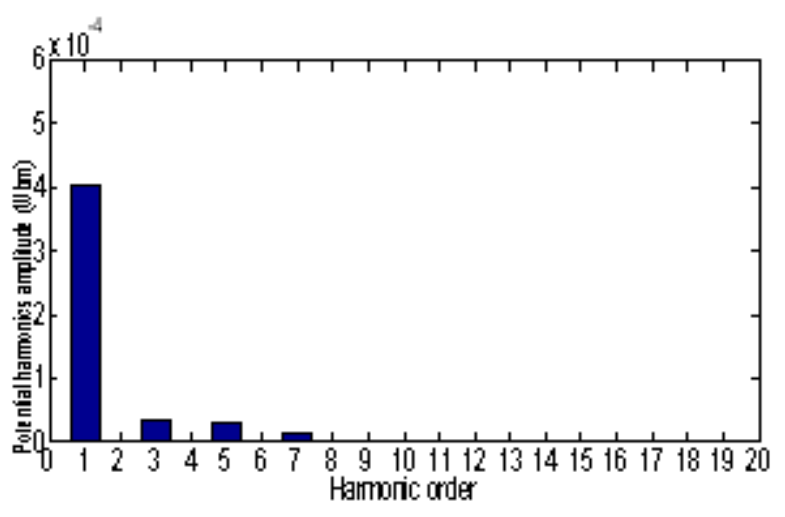

Fig.7 Frequency spectrum of the stator-core magnetic-potential harmonics.

The magnetic potential distribution computed in several points of the stator core is represented by Fig.6. The frequency spectrum of magnetic potential harmonics is presented in Fig.7. Here, the dominant harmonic is the first-order harmonic, followed by odd harmonics of third, fifth and seventh orders.

\section{SLOTTING EFFECT}

The effect of stator slots on the no-load magnetic flux distribution is investigated. The airgap flux density always drops at stator slot openings, and this effect has a significant influence on the values of the flux and back-emf. For this reason, it is important to accurately model the airgap flux density.

The maximum flux of a certain pole can be found when a rotor-PM is located so that its centerline is coincident with that of a stator tooth. Accordingly, integrating the positive flux pulse under the tooth gives the maximum flux per pole.

The 2-D representation of one pole of the AFBPMM machine and the no-loadmagnetic flux distribution in the airgap are shown in Fig.8.

Fig. 9 presents the angular variation of the airgap magnetic flux density due to the rotor-PMs.

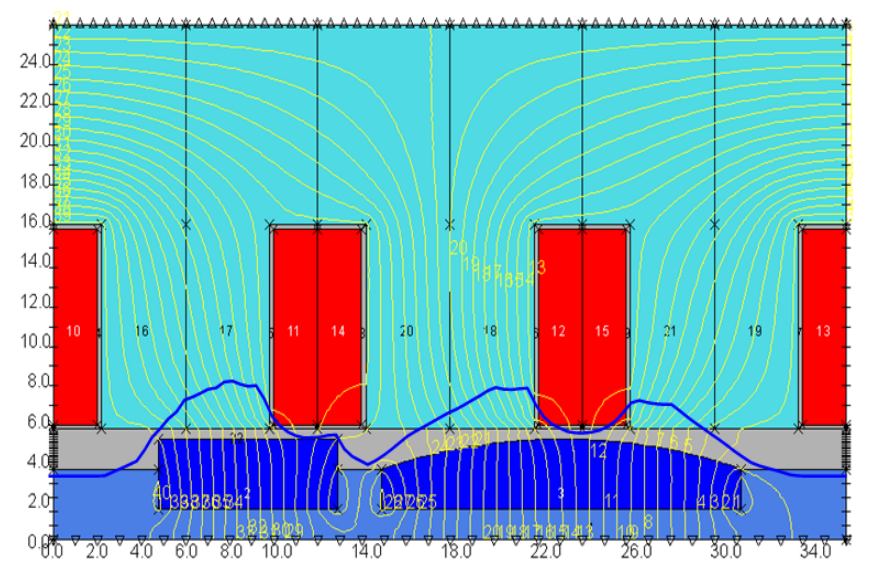

Fig.8 No-load magnetic flux distribution for one PM-rotor pole.

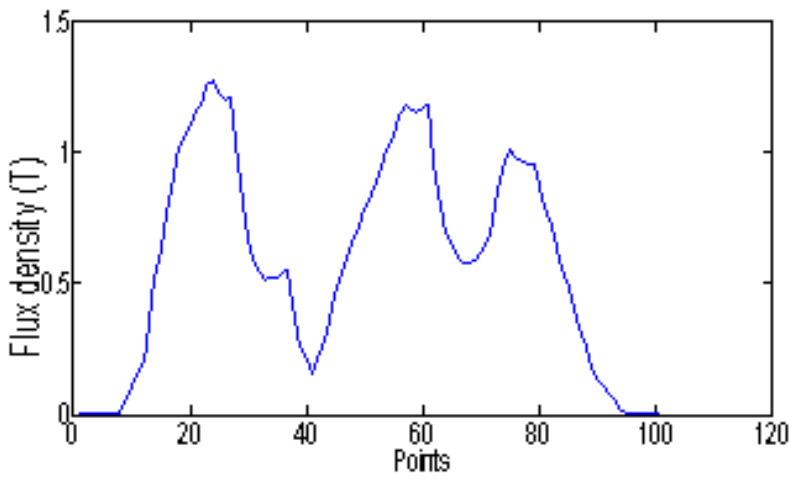

Fig.9 Airgap magnetic flux-density due to rotor-PMs.

\section{OPEN-CIRCUIT NO-LOAD BACK-EMF}

A comparison between FE-computed flux-related values and the experimental ones is provided. Hence, no-load tests were performed under open-circuit (generator-mode) conditions using the DC machine drive as a prime mover. The no-load test was done to evaluate the back-emf and to measure the armature-winding resistance and inductance.

The back-emf measurements were carried out for a nominal speed of $1500 \mathrm{rpm}$. The voltage measurements are made with the high-precision voltage oscilloscope probe. The test results captured on the oscilloscope are presented in Fig.10. The open-circuit backemfs at no-load for clockwise and counter-clockwise rotation are presented in Fig.11 and Fig.12, respectively. Both back-emf waveforms are comparatively shown in Fig. 13.

The FE-computed (using Opera 2D software) back-emf is presented in Fig. 14.

The simulated and experimental results are in good agreement, as proven by Fig. 15 .

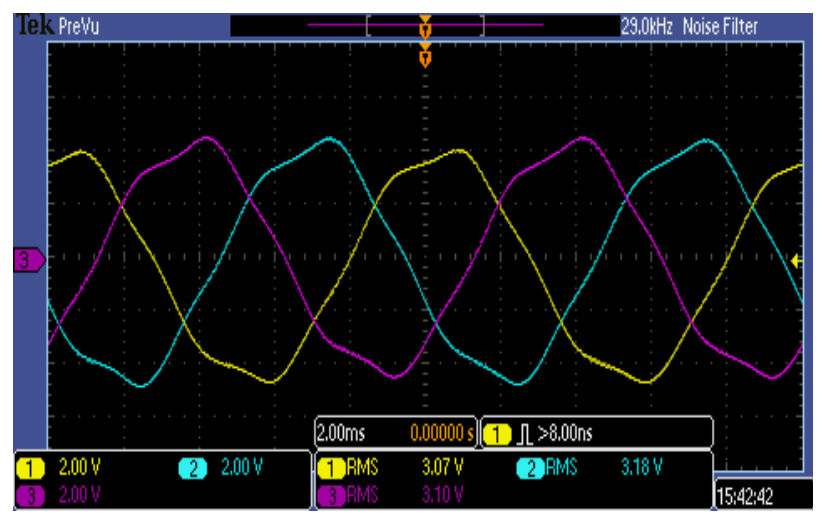

Fig.10 Experimental open-circuit (no-load ) back-emf waveform captured on the oscilloscope

\section{CONCLUSIONS}

A small double-sided AFBPMM has been presented in this paper. To verify the effectiveness of the design tool, as well as to get manufacturing expertise a prototype machine was constructed. 

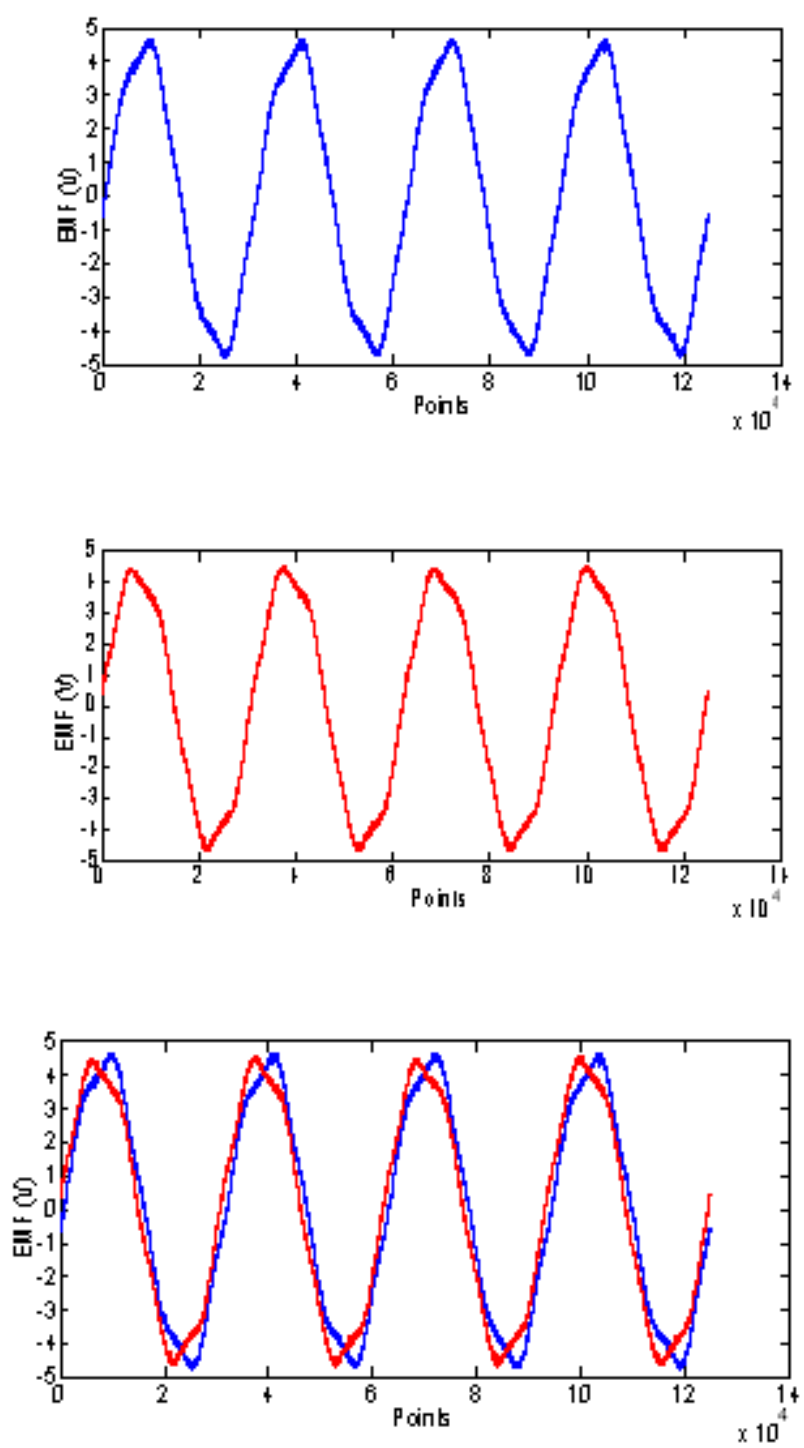

Fig.13 Comparative experimental open-circuit (no-load) backemfs for clockwise and counter-clockwise rotation.
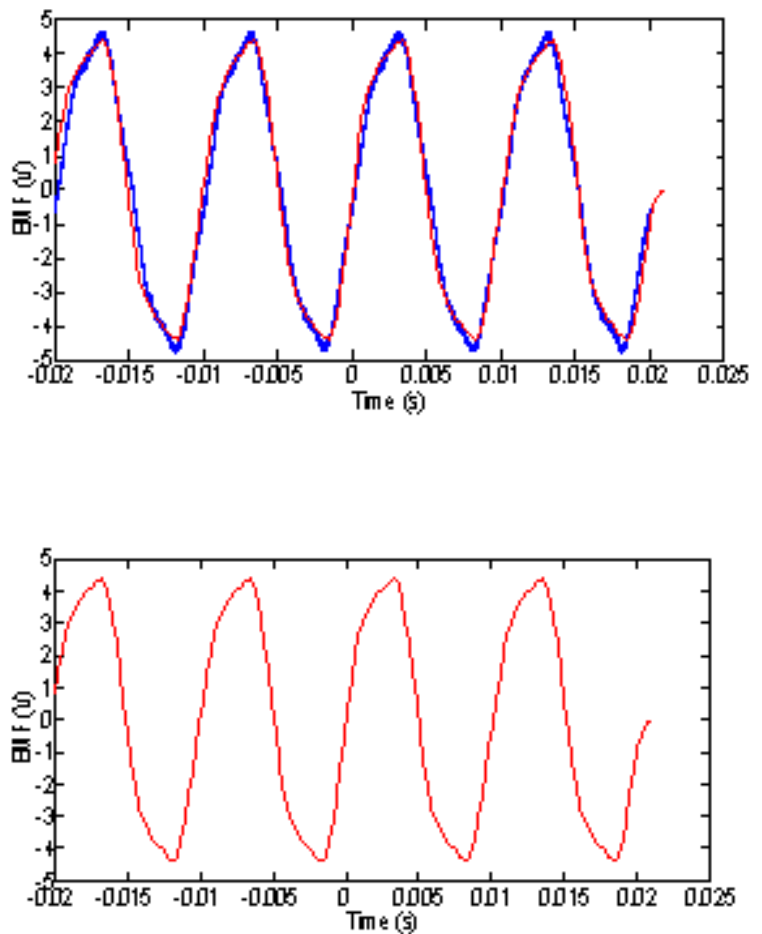

For the built prototype AFBPMM, the back-emfs, armature-winding resistance and inductance parameters were measured under open-circuit (no-load) condition.

FE field analysis models have been developed to predict the AFBPMM flux density distribution and developed torque. FE-computed and measured results, for the open-circuit (no-load) back-emf have been compared, showing good agreement.

The prototype AFBPMM proposed in this paper appears potentially suitable for light electric traction and automotive applications.

\section{REFERENCES}

[1] A.Egea, G.Almandoz1, J.Poza and A.Gonzalez, "Analytic Model of Axial Flux Permanent Magnet Machines Considering Spatial Harmonics", International Symposium on Power Electronics, Electrical Drives, Automation and Motion - SPEEDAM 2010.

[2] Parviainen, A., Niemelä, M., Pyrhönen, J., 2003a. "Analytical, 2D FEM and 3D FEM modeling of PM axial-flux machines ", Proceedings of 10th European Conference on Power Electronics and Applications - EPE 2003, CD-ROM.

[3] J. F. Gieras, R. Wang, and M. J. Kamper, "Axial Flux Permanent Magnet Brushless Machines", 2004 Kluwer.

[4] N. Chaker, I. B. Salah, S. Tounsi and R. Neji, "Design of Axial-Flux Motor for Traction Application" Journal of Electromagnetic Analysis and Applications, 2009, 2, pp. 7383.

[5] Seyyed Mehdi Mirimani, Abolfazl Vahedi, "Developing a 3DFEM Model for Electromagnetic Analysis of an Axial Flux Permanent Magnet Machine" Journal of Electromagnetic Analysis and Applications, 2010, 2, pp.258-263.

[6] S. Tounsi, F. Gillon, S. Brisset, P. Brochet, R. Neji, "Design of an axial flux brushless DC motor for electric vehicle", Proceedings of International Conference on Electrical Machines - ICEM 2002, CD-ROM.

[7] Z. Zhang, F. Profumo, A. Tenconi, "Design of an axial flux interior PM synchronous motor with a wide speed range", Proceedings of International Conference on Electrical Machines - ICEM 1996, Vol. III, pp. 273-278.

[8] Brushless Permanent Magnet Motor Tutorial, Flux 2D version 7.5, Cedrat, March 2001.

[9] A. Parviainen, "Design of Axial-flux Permanent Magnet Lowspeed Machines and Performance Comparison between Radial-flux and Axial-flux Machines", Ph.D. Thesis, Lappeenranta University of Technology, Finland, 2005

[10] C.H. Lim, G. Airoldi, J.R. Bumby, R.G. Dominy, G.I. Ingram, K. Mahkamov, N.L. Brown, a Mebarki, and M. Shanel, "Experimental and

CFD investigation of a lumped parameter thermal model of a singlesided, slotted axial flux generator," International Journal of Thermal Sciences, vol. 49, Sep. 2010, pp. 17321741.

[11] Z.Q. Zhu, D. Howe, E. Bolte and B. Ackermann, "Instantaneous Magnetic Fiel Distribution in Brushless Permanent Magnet DC Motors I: Open-circuit Field", IEEE Transactions on Magnetics, vol. 29, no. 1, pp. 124-135, 1993

[12] S. Tounsi, "Modélisation et optimisation de la motorisation et de l'autonomie d'un véhicule électrique," Thèse de doctorat, Ecole Nationale d'Ingénieurs de Sfax, Tunisia, 2006. 